\title{
Does size matter? Separations on guard columns for fast sample analysis applied to bioenergy research
}

\author{
Stefan Bauer ${ }^{*}$ and Ana B. Ibáñez
}

\begin{abstract}
Background: Increasing sample throughput is needed when large numbers of samples have to be processed. In chromatography, one strategy is to reduce column length for decreased analysis time. Therefore, the feasibility of analyzing samples simply on a guard column was explored using refractive index and ultraviolet detection. Results from the guard columns were compared to the analyses using the standard $300 \mathrm{~mm}$ Aminex HPX-87H column which is widely applied to the analysis of samples from many biotechnology- and bioenergy-related experiments such as biomass conversions or fermentations.
\end{abstract}

Results: The $50 \mathrm{~mm}$ Rezex RFQ Fast Acid $\mathrm{H}^{+}$guard column was able to separate the most common fermentation products (ethanol, acetone, iso- and n-butanol) and promising precursors (furfural and 5-hydroxymethylfurfural) of biofuels and value-added chemicals. Compound profiles in fermentation samples were analyzed with similar accuracy compared to results using the $300 \mathrm{~mm}$ column. However, separation of glucose and xylose was not achieved. Nevertheless, it was possible to monitor the consumption of one of the two sugars during fermentation if the other one was absent or remained constant over the course of the experiment. If correct peak integration and interference subtraction was applied, concentration profiles from enzymatic digestibility experiments and even more complex samples (e.g. acetone-butanol-ethanol (ABE) fermentation) were reliably obtained. With the $50 \mathrm{~mm}$ guard column, samples were analyzed up to ten-times faster compared to the $300 \mathrm{~mm}$ column. A further decrease in analysis time was achieved by using the $30 \mathrm{~mm}$ Micro Guard Cation $\mathrm{H}$ guard column. This column is especially suitable for the rapid analysis of compounds with long elution times on the standard $300 \mathrm{~mm}$ column, such as biofuel-related alcohols (e.g., n-butanol, n-hexanol) and furan- and tetrahydrofuran-type molecules.

Conclusion: Applied to a suitable set of samples, separations on a guard column can give rapid and sufficiently accurate information on compound changes over the course of an experiment. Therefore, it is an inexpensive and ideal tool for processing a large amount of samples, such as in screening or discovery experiments, where detecting relative changes is often sufficient to identify promising candidates for further analysis.

Keywords: Ion exclusion chromatography, Aminex HPX-87H, Rezex RFQ, Micro Guard Cation H, Enzymatic digestibility assay, Glucose, Ethanol, Butanol, Furans, Fermentation

\footnotetext{
* Correspondence: stefan.bauer@berkeley.edu

Energy Biosciences Institute, University of California, Berkeley, CA 94720, USA
} 


\section{Background}

A popular liquid chromatography column used for the analysis of biomass conversion and fermentation products is based on a polymer matrix of polystyrene-divinylbenzene (e.g. Bio-Rad Aminex HPX-87H, Phenomenex Rezex ROA and RFQ, Shodex SH1821, Sigma-Aldrich Supelcogel $\mathrm{C} 610 \mathrm{H}$ and others) [1-6]. It is operated in isocratic elution mode enabling the connection to a refractive index detector (RID) which provides universal compound detection. This set up allows for analysis of a wide range of compounds. With a standard $300 \mathrm{~mm}$ length, this type of column provides baseline separation of the main cell wall sugars (glucose, xylose and arabinose) of many lignocellulosic biomass feedstocks. This column is also used for the analysis of organic acids, alcohols (e.g., ethanol, n-butanol) and sugar degradation products (e.g., 5hydroxymethylfurfural, furfural) [7-10]. It only requires acidified water as mobile phase and only minimal sample preparation.

Typical HPLC methods aim to separate complex mixtures in order to individually detect isolated compounds particularly when a non-specific detector like RID is used. In our experience from supporting researchers in an organization comprising more than 500 scientists dedicated to bioenergy research, many analytical questions can be reduced to identifying the change in a few compounds over the course of the experiment. Furthermore, reducing analysis time is often more important than obtaining precise absolute quantification data. This is especially true for the results from screening experiments involving a larger amount of samples. The detection of relative changes is often sufficient to identify promising candidates for further analysis.

Fast methods targeting individual compounds in complex mixtures have previously been established and include, for example, gas chromatography [11] spectroscopy [12], or enzymatic assays, such as for sugars, sugar alcohols, organic acids, and ethanol [13-17]. Several of these target analytes can even be measured in an automated mode using a biochemistry analyzer (YSI) and results are obtained in minutes [18]. However, all such methods either require costly equipment or individual analysis kits for every single analyte. Therefore, it is tempting to use existing analytical instrumentation (HPLC) and reduce analysis time for higher sample throughput. In this respect, Scarlata and Hyman [6] have successfully shown that reducing the column length to $100 \mathrm{~mm}$ (plus a $30 \mathrm{~mm}$ guard column) can reduce the analysis time by a factor of five compared to the $300 \mathrm{~mm}$ column, but still provide adequate accurate results from a biomass compositional analysis (glucose, xylose, arabinose, acetate, 5-hydroxymethylfurfural, furfural). In our studies, we explored a further reduction of the analysis time by using only a guard column as the simplest and most basic column available. For this purpose, samples generated by various research groups in our institute were analyzed on the standard $300 \mathrm{~mm}$ Aminex HPX-87H column and compared to results obtained from an analysis on a guard column (50 mm Rezex RFQ Fast Acid $\mathrm{H}^{+}$as well as $30 \mathrm{~mm}$ Micro Guard Cation H).

\section{Results and discussion}

A short column length is often used for faster separation especially in conjunction with mass spectrometric detection. These shorter columns have usually smaller particle sizes $(3.5 \mu \mathrm{m}$ and lower) which greatly improve resolution. However, columns like the Aminex HPX-87H operate in a mixture of size- and ion-exchange/exclusion. They consist of a resin with a rather large particle size $(8-9 \mu \mathrm{m})$. As a result, a reduction in column length significantly lowers column efficiency. For example, a reduction of the column length to $50 \mathrm{~mm}$ results in practically unresolved glucose and xylose (see peak 1 and 2 in Fig. 6a). These types of columns can therefore not be directly compared to other columns. Despite the lower separation efficiency, the shorter columns can still provide adequate chromatographic resolution when used with appropriate samples in which compounds co-eluting with the target analytes are either not present or their concentration is sufficiently low so they do not significantly interfere with quantification.

Figure 1 shows the elution profile of some of the most common fermentation products (ethanol, acetone, isobutanol, n-butanol) and sugar degradation products (5hydroxymethylfurfural (5-HMF), furfural) on the $50 \mathrm{~mm}$ Rezex RFQ Fast Acid $\mathrm{H}^{+}$guard column ("50 mm guard column") operated at different temperatures at a flow rate of $1.0 \mathrm{~mL} / \mathrm{min}$. The degradation products $5-\mathrm{HMF}$ and furfural are promising precursors for the generation of biofuels and value-added chemicals [3, 19, 20]. Good separation of all these compounds is achieved at a column temperature of $30{ }^{\circ} \mathrm{C}$ (Fig. 1a). At this temperature, ethanol (peak 1) and acetone (peak 2) are almost baseline separated. By increasing the column temperature the alcohols elute later and 5-HMF (peak 5) and furfural (peak 6) elute earlier. The retention time of acetone (peak 2 ) is practically not affected by temperature (Fig. 1a-c). Ethanol/acetone (peak 1/peak 2) separation is deteriorated at a higher temperature and 5-HMF (peak 5) is coeluting with n-butanol (peak 4) at $55{ }^{\circ} \mathrm{C}$ (Fig. 1b) and with iso-butanol (peak 3) at $80{ }^{\circ} \mathrm{C}$ (Fig. 1c). The column temperature must therefore be chosen based on the sample composition so that target analytes do not overlap. For example, as mentioned above, a temperature of $30^{\circ} \mathrm{C}$ has to be applied for successful separation of ethanol and acetone. This column temperature is also beneficial for the faster elution of iso-and n-butanol (Fig. 1a). In contrast, 5-HMF and furfural are eluted faster at a higher temperature. However, depending on which butanol isomer 


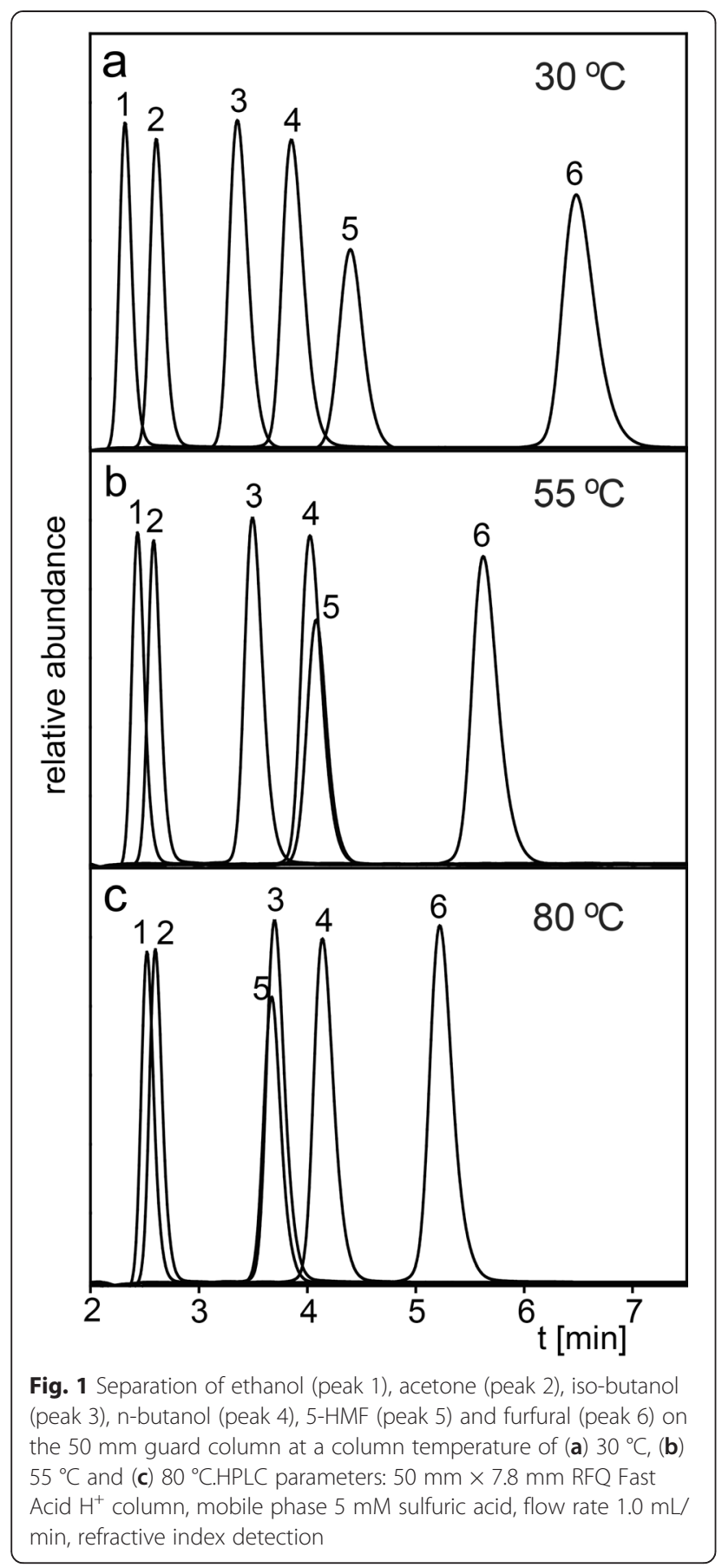

is present, the column temperature needs to be correctly chosen since 5 -HMF coelutes either with n-butanol at $55^{\circ} \mathrm{C}$ (Fig. 1b) or iso-butanol at $80{ }^{\circ} \mathrm{C}$ (Fig. 1c).

Using a $20 \mu \mathrm{L}$ injection volume, the determined linear calibrations for the compounds under study ranged from $0.005-0.02 \mathrm{mg} / \mathrm{mL}$ to $50 \mathrm{mg} / \mathrm{mL}(20 \mathrm{mg} / \mathrm{mL}$ for glucose and xylose) with RI and UV detection (Table 1). UV detection $(280 \mathrm{~nm})$ resulted in an about 100-fold increased
Table 1 Calibration results for each compound

\begin{tabular}{llll}
\hline Compound & Detection & Linear quantification range & $\begin{array}{l}\text { Regression } \\
\text { coefficient }\end{array}$ \\
\hline Ethanol & RID & $0.01-50 \mathrm{mg} / \mathrm{mL}$ & 0.9995 \\
Acetone & RID & $0.01-50 \mathrm{mg} / \mathrm{mL}$ & 0.9996 \\
& UV $265 \mathrm{~nm}$ & $0.01-50 \mathrm{mg} / \mathrm{mL}$ & 0.9999 \\
& UV $285 \mathrm{~nm}$ & $0.02-50 \mathrm{mg} / \mathrm{mL}$ & 0.9995 \\
iso-Butanol & RID & $0.005-50 \mathrm{mg} / \mathrm{mL}$ & 0.9999 \\
n-Butanol & RID & $0.005-50 \mathrm{mg} / \mathrm{mL}$ & 0.9997 \\
5-HMF & RID & $0.005-50 \mathrm{mg} / \mathrm{mL}$ & 0.9999 \\
& UV $280 \mathrm{~nm}$ & $0.00005-0.25 \mathrm{mg} / \mathrm{mL}$ & 0.9999 \\
Furfural & RID & $0.005-50 \mathrm{mg} / \mathrm{mL}$ & 0.9995 \\
& UV $280 \mathrm{~nm}$ & $0.00005-0.25 \mathrm{mg} / \mathrm{mL}$ & 0.9999 \\
Glucose & RID & $0.005-20 \mathrm{mg} / \mathrm{mL}$ & 0.9999 \\
Xylose & RID & $0.005-20 \mathrm{mg} / \mathrm{mL}$ & 0.9999
\end{tabular}

Chromatography conditions: $50 \mathrm{~mm} \times 7.8 \mathrm{~mm}$ RFQ Fast Acid $\mathrm{H}^{+}$kept at $30^{\circ} \mathrm{C}$, flow rate: $1.0 \mathrm{ml} / \mathrm{min}$ of $5 \mathrm{mM}$ sulfuric acid, $20 \mu \mathrm{L}$ injection volume; Lower limit of the calibration range was determined as the concentration level with a relative standard deviation (RSD) $<10 \%(n=5)$

sensitivity for 5-HMF and furfural compared to RI detection (calibration range $50 \mathrm{ng} / \mathrm{mL}-0.25 \mathrm{mg} / \mathrm{mL}$ ).

Since $80{ }^{\circ} \mathrm{C}$ is close to the maximum operating temperature of the column $\left(85{ }^{\circ} \mathrm{C}\right)$, we chose a column temperature of $55{ }^{\circ} \mathrm{C}$ for most of the following experiments. This is good balance between fast analysis time and column life time.

\section{Application to analysis of $\mathrm{n}$-butanol and iso-butanol production during fermentations}

These two alcohols elute later than most other components present in the fermentation media. Fig. 2a shows a representative chromatogram from an E.coli fermentation producing n-butanol (peak 1) which eluted at $3.7 \mathrm{~min}$. Fig. $2 \mathrm{~b}$ shows the determined $\mathrm{n}$-butanol production of three $E$. coli strains after incubation for $24 \mathrm{~h}, 48 \mathrm{~h}$ and $72 \mathrm{~h}$. The n-butanol profile obtained with the $50 \mathrm{~mm}$ guard column was very similar compared to the 300 mm Bio-Rad HPX-87H column (“300 mm column”). Values reached 90.9-98.0\% of the values obtained with the longer column (except for the BW25113 values which reached only 80.7-84.1 \% due to the low concentration affecting accuracy). The DH1 strain is able to produce more n-butanol than BW25113, which almost showed no significant n-butanol levels. Usually, BW25113 produces about half the concentration of DH1 (Niwen Kong, personal communication). Unexpectedly, the BW25113 strain used in this experiment did not perform as expected. The deletion of AcrB efflux pumps in DH1 $\triangle a c r B$ lead to even higher n-butanol levels. AcrB pumps are large proteins and are used to actively secret n-butanol from the cell. However, they can be considered "energy 


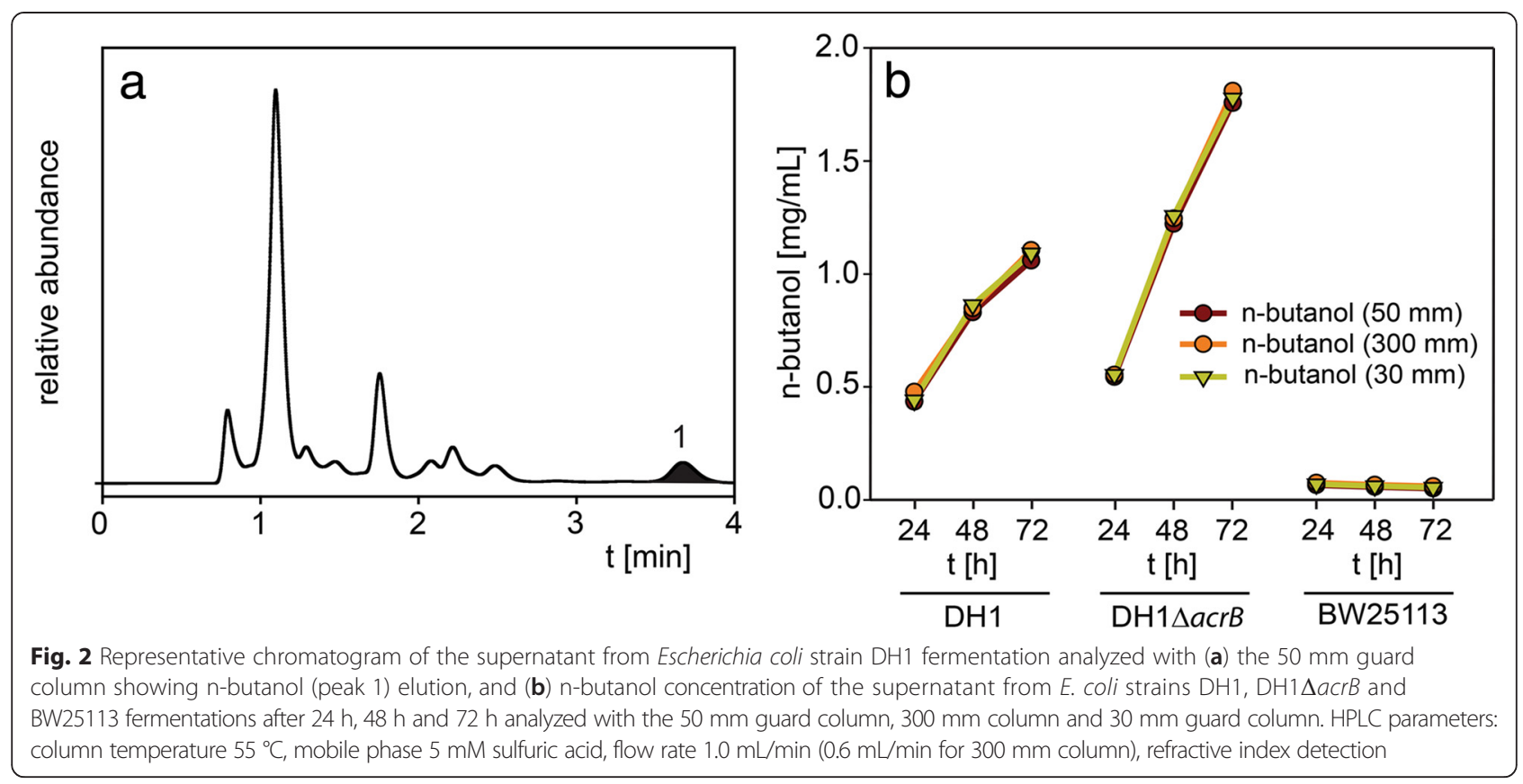

drainers" since they use a big portion of the cellular resources needed for n-butanol synthesis. At the levels measured here, n-butanol is not toxic for the E. coli cells and therefore the AcrB pumps present in the DH1 strain are not a "de-toxification"-advantage over the DH1 1 acrB strain which has more energy resources available for n-butanol production.

A similar chromatogram was obtained for iso-butanol production from E. coli strains sFAB5441 and sFAB5692
(Fig. 3a). Iso-butanol (peak 1) eluted at $3.4 \mathrm{~min}$ in a region where no interference from other media components were expected. The values measured with the $50 \mathrm{~mm}$ guard column were again almost identical to the ones obtained with the $300 \mathrm{~mm}$ column (in the range of 96.7-100.4\%, Fig. 3b). In this experiment, the decrease of iso-butanol after $48 \mathrm{~h}$ for the sFAB 5441 strain was explained by evaporation due to a leak in the cap of the flask.
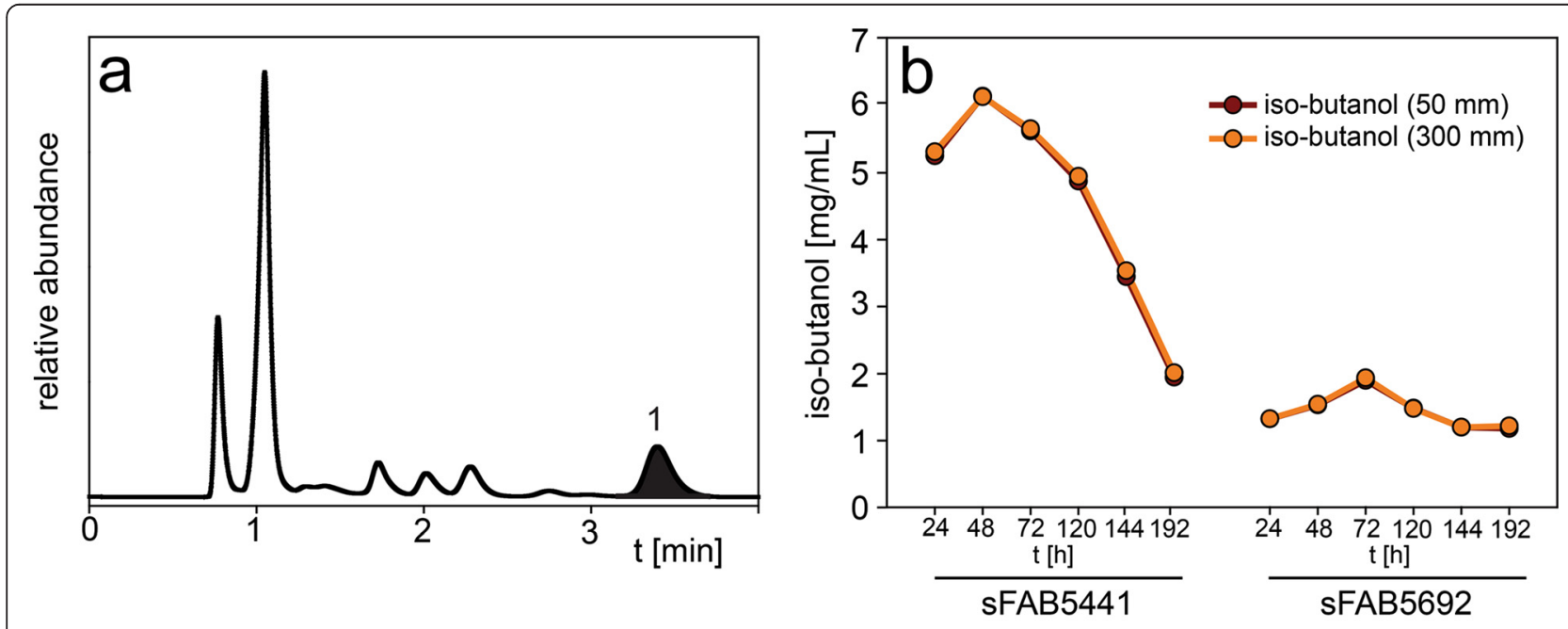

Fig. 3 Representative chromatogram of the supernatant from Escherichia coli strain sFAB5692 fermentation analyzed with (a) the $50 \mathrm{~mm}$ guard column showing iso-butanol (peak 1) elution, and (b) iso-butanol concentration profile of the supernatant from E. coli strains sFAB5441 and sFAB5692 fermentation between $24 \mathrm{~h}$ and $192 \mathrm{~h}$ analyzed with the $50 \mathrm{~mm}$ guard column and $300 \mathrm{~mm}$ column. HPLC parameters: column temperature $55^{\circ} \mathrm{C}$, mobile phase $5 \mathrm{mM}$ sulfuric acid, flow rate $1.0 \mathrm{~mL} / \mathrm{min}(0.6 \mathrm{~mL} / \mathrm{min}$ for $300 \mathrm{~mm}$ column), refractive index detection 
The analysis of $\mathrm{n}$ - and iso-butanol was performed with a 4 min total run time and this is about 9-10 times faster compared to the standard $300 \mathrm{~mm}$ column.

\section{Application to analysis of 5-hydroxymethylfurfural (5-HMF) and furfural}

5-HMF and especially furfural are compounds with long elution times on the standard $300 \mathrm{~mm}$ HPX-87H column (at a flow rate of $0.6 \mathrm{~mL} / \mathrm{min}$ and $50{ }^{\circ} \mathrm{C}$ about 34 and $52 \mathrm{~min}$, respectively). Experiments requiring the analysis of these compounds often include determination of the degree of their removal or reduction during membrane detoxification of hydrolysate [21] or the rate of sugar degradation during pretreatment or conversion steps $[9,10]$. For the purpose of this study, three biomass hydrolysates prepared under different severity conditions were analyzed. Fig. 4a depicts the elution profiles for the two compounds on the $50 \mathrm{~mm}$ guard column. Hydrolysate 1 was prepared with a lower sulfuric acid concentration $(0.5 \%)$ and incubated at a lower temperature $\left(158{ }^{\circ} \mathrm{C}\right)$ causing less sugar degradation. Therefore, it shows a lower 5-HMF (peak 1) and a lower furfural (peak 2) concentration compared to the other two hydrolysates which were prepared with a higher acid concentration ( $1 \%$ and $1.5 \%$, respectively) and a higher temperature $\left(180{ }^{\circ} \mathrm{C}\right.$ and $190{ }^{\circ} \mathrm{C}$, respectively). As illustrated in Fig. $4 \mathrm{~b}$, the 5 -HMF analysis results with the $50 \mathrm{~mm}$ guard column compared to the $300 \mathrm{~mm}$ column were lower for hydrolysate 1 (88.2\%, 0.15 vs. $0.17 \mathrm{mg} / \mathrm{mL})$, lower for hydrolysate $2(93.6 \%, 1.31 \mathrm{vs} 1.40 \mathrm{mg} / \mathrm{mL})$ and lower for hydrolysate 3 ( $84.1 \%, 0.74$ vs. $0.88 \mathrm{mg} / \mathrm{mL})$. However, the furfural amounts determined with the $50 \mathrm{~mm}$ guard column were in the range of $96.8 \%-103.8 \%$ of the $300 \mathrm{~mm}$ column results $(1.49$ vs. $1.54 \mathrm{mg} / \mathrm{mL}, 1.81$ vs.
$1.87 \mathrm{mg} / \mathrm{mL}$, and 2.46 vs. $2.37 \mathrm{mg} / \mathrm{mL}$, respectively) and can be considered very comparable. In conclusion, the different pretreatment severity profiles were adequately reflected by analysis with the $50 \mathrm{~mm}$ guard column.

\section{Application to analysis of ethanol production and xylose and glucose consumption during fermentations}

When glucose and xylose are present in a mixture, their accurate determination using the $50 \mathrm{~mm}$ guard column is challenging since the separation of these two sugars is practically not possible. However, the analysis can be performed when either one of the two is present in high abundance or one of the two monosaccharides concentrations is constant over the course of the experiment. Ethanol eluted at 2.2 min which was close to other fermentation media compounds but was still sufficiently isolated for selective measurement in these experiments (Fig. 5a, Fig. 6a-c).

The consumption of xylose and production of ethanol of a modified Saccharomyces cerevisiae strain analyzed with the $50 \mathrm{~mm}$ guard column and $300 \mathrm{~mm}$ column is shown in Fig. 5b and a representative chromatogram is shown in Fig. 5a. The xylose amounts measured with the $50 \mathrm{~mm}$ guard column were in the range of 100.5$105.4 \%$ and the ethanol amounts were in the range of 97.7-101.9 \% (except for the two lower concentrations) of the values obtained with the $300 \mathrm{~mm}$ column. The two lower concentrations of ethanol showed $255.6 \%$ (0.23 vs. $0.09 \mathrm{mg} / \mathrm{mL})$ and $115.6 \%$ (0.89 vs. $0.77 \mathrm{mg} / \mathrm{mL})$ deviation most likely due to interfering co-eluting compounds at these lower concentrations. Overall, the consumption/production profile measured with the $50 \mathrm{~mm}$ guard column is very similar to the one obtained with the $300 \mathrm{~mm}$ column. However, the total run time using the $50 \mathrm{~mm}$ guard
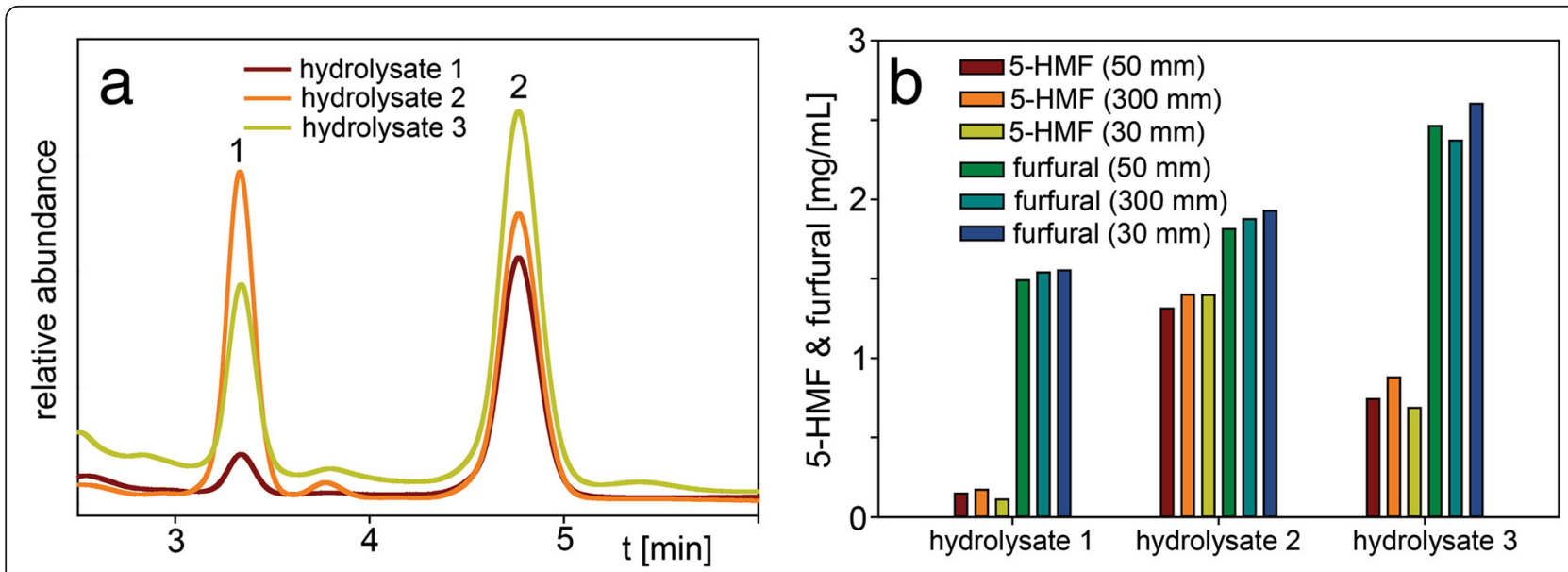

Fig. 4 Chromatogram of hydrolysate 1, hydrolysate 2 and hydrolysate 3 analyzed with (a) the 50 mm guard column showing 5-HMF (peak 1) and furfural (peak 2) elution, and (b) 5-HMF and furfural concentrations of hydrolysate 1, hydrolysate 2 and hydrolysate 3 analyzed with the 50 mm guard column, $300 \mathrm{~mm}$ column and $30 \mathrm{~mm}$ guard column. HPLC parameters: column temperature $55^{\circ} \mathrm{C}$, mobile phase $5 \mathrm{mM}$ sulfuric acid, flow rate $1.0 \mathrm{~mL}$ min $(0.6 \mathrm{~mL} / \mathrm{min}$ for $300 \mathrm{~mm}$ column), refractive index detection 

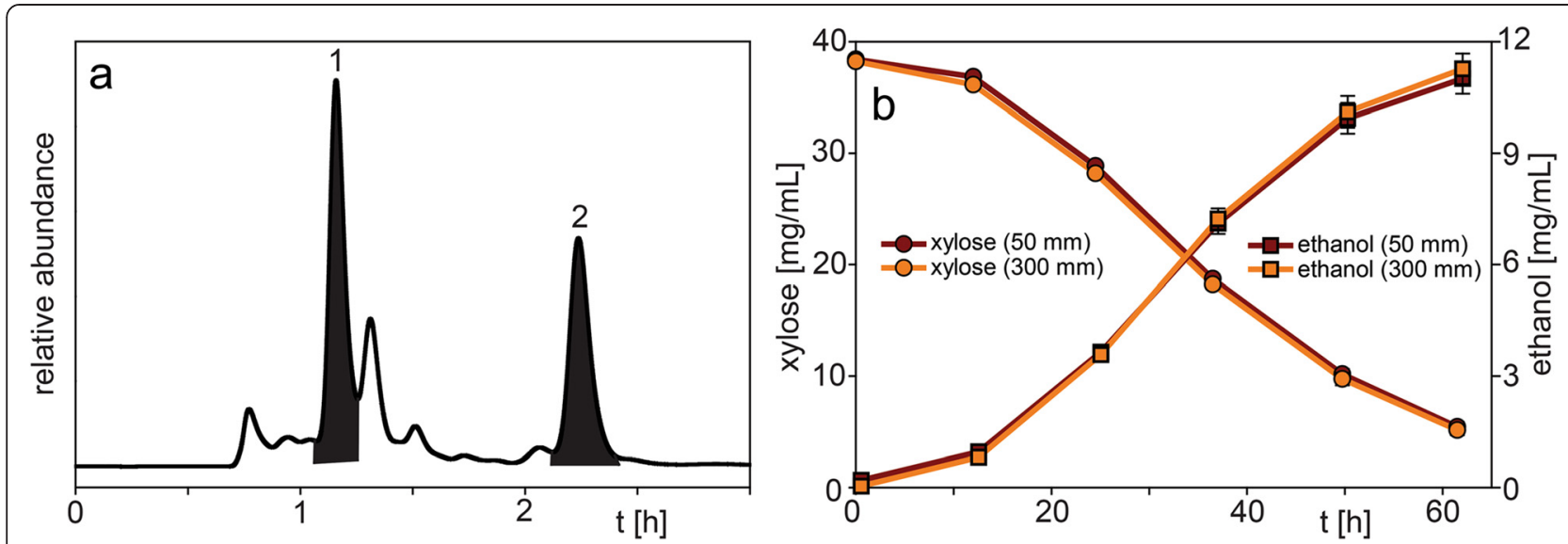

Fig. 5 Representative chromatogram of the supernatant from a Saccharomyces cerevisiae SA-1-X123 strain fermentation analyzed with (a) the $50 \mathrm{~mm}$ guard column showing xylose (peak 1) and ethanol (peak 2) elution, and (b) xylose and ethanol concentration profile of the supernatant from a modified S. cerevisiae strain fermentation between $0 \mathrm{~h}$ and $62 \mathrm{~h}$ analyzed with the $50 \mathrm{~mm}$ guard column and $300 \mathrm{~mm}$ column. HPLC parameters: column temperature $55^{\circ} \mathrm{C}$, mobile phase $5 \mathrm{mM}$ sulfuric acid, flow rate $1.0 \mathrm{~mL} / \mathrm{min}(0.6 \mathrm{~mL} / \mathrm{min}$ for $300 \mathrm{~mm}$ column), refractive index detection
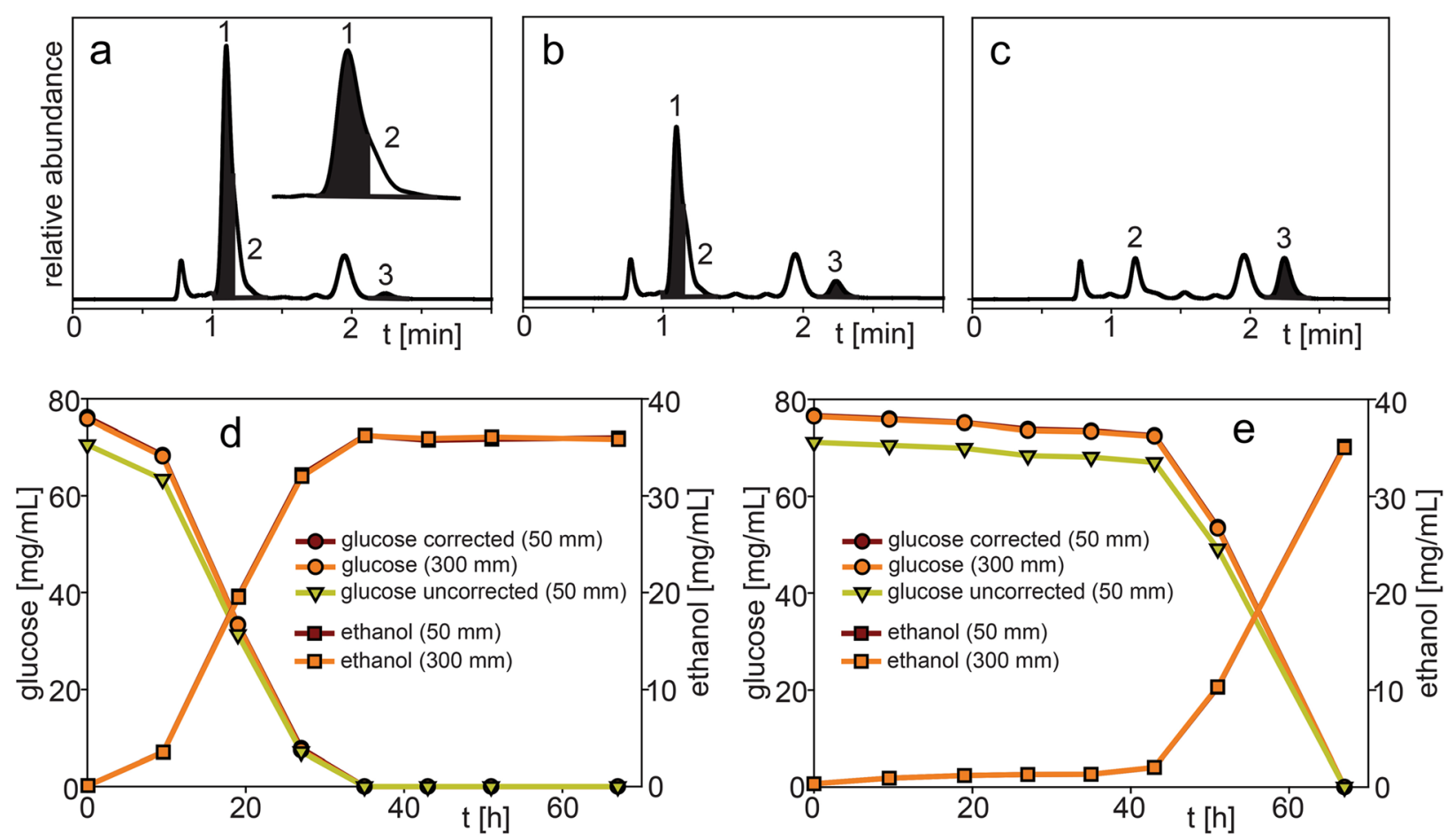

Fig. 6 Chromatogram of the supernatant from Saccharomyces cerevisiae SA-1 strain fermentation supplemented with $25 \%$ of pH adjusted hydrolysate 3 analyzed with the $50 \mathrm{~mm}$ guard column showing glucose (peak 1), xylose (peak 2) and ethanol (peak 3 ) elution after (a) $42 \mathrm{~h}$, (b) $50 \mathrm{~h}$ and (c) $67 \mathrm{~h}$, and xylose and ethanol concentration profile of the supernatant between $0 \mathrm{~h}$ and $62 \mathrm{~h}$ from a S. cerevisiae SA-1 strain fermentation supplemented with (d) $25 \%$ of pervaporation detoxified hydrolysate 3 and (e) $25 \%$ of pH adjusted hydrolysate 3, analyzed with the $50 \mathrm{~mm}$ guard column and $300 \mathrm{~mm}$ column. HPLC parameters: column temperature $55^{\circ} \mathrm{C}$, mobile phase $5 \mathrm{mM}$ sulfuric acid, flow rate $1.0 \mathrm{~mL} / \mathrm{min}(0.6 \mathrm{~mL} / \mathrm{min}$ for $300 \mathrm{~mm}$ column), refractive index detection 
column was only $3 \mathrm{~min}$ and ethanol elution was completed at $2.5 \mathrm{~min}$. This is about 10 times faster compared to the $300 \mathrm{~mm}$ column.

In another experiment, $S$. cerevisiae SA-1 was grown in a medium supplemented with $25 \%$ hydrolysate 3 that was either $\mathrm{pH}$ adjusted or detoxified by membrane pervaporation which reduced the concentration of toxic compounds such as furfural, formic and acetic acid [21]. The hydrolysate was obtained by a dilute acid and heat pretreatment of Miscanthus biomass in order to release hemicellulosic sugars and improve cellulose digestibility. During this process, the harsh conditions lead to sugar and lignin degradation resulting in the production of a fleet of fermentation inhibitors like furans, phenolics and organic acids which could also interfere with the analysis [22, 23]. Representative chromatograms of the sample with $\mathrm{pH}$-adjusted hydrolysate at time points $42 \mathrm{~h}, 50 \mathrm{~h}$ and $67 \mathrm{~h}$ analyzed with the $50 \mathrm{~mm}$ guard column are shown in Fig. 6a-c. A decrease of glucose (peak 1) and increase of ethanol (peak 3) can be observed over the time course whereas the remaining chromatogram is mostly the same. The inset in Fig. 6a shows the close elution of glucose (peak 1) and xylose (peak 2) resulting in a peak with a shoulder making accurate integration difficult. Fig. $6 \mathrm{~d}$ and $6 \mathrm{e}$ show the measured glucose and ethanol concentrations over the course of the experiments with the membrane-detoxified hydrolysate and the $\mathrm{pH}$-adjusted hydrolysate, respectively. The values for "glucose uncorrected" were obtained when the attempt was made to integrate glucose separately from the closely-eluting xylose peak (Fig. 6a inset). The determined "glucose uncorrected" concentrations for experiments with the $\mathrm{pH}$-adjusted and with the detoxified hydrolysate were 91.0-93.6 \% and 91.6$93.0 \%$, respectively, of the concentrations obtained when analyzed with the $300 \mathrm{~mm}$ column. This indicates that xylose interfered with a correct glucose area determination. The ethanol concentrations were almost identical with 99.4-100.6 \% and 99.5-100.2 \%, respectively, compared to the results of the $300 \mathrm{~mm}$ column. When glucose and xylose were integrated together as one peak and the area of the xylose peak (peak 2, Fig. 6c) of the $67 \mathrm{~h}$ time point was subtracted (where glucose concentration was close to 0), "glucose corrected" values were obtained which were closer to the results of the $300 \mathrm{~mm}$ column (94.8-100.6 \% and 99.5-99.9 \%, respectively). Even without glucose correction, the effect of the toxic hydrolysate on delaying the glucose fermentation and production of ethanol until around $42 \mathrm{~h}$ into the fermentation was clearly observed with the $50 \mathrm{~mm}$ column (Fig. 6e).

\section{Application to analysis of glucose release from enzymatic digestibility assays of pretreated biomass}

The enzymatic release of glucose from cellulose after biomass pretreatment is often performed not only to determine of the effectiveness of the pretreatment itself but also for the evaluation of the hydrolytic potential of new enzymes. A commonly used method is the pretreatment of biomass with dilute acid (e.g. sulfuric acid) at higher temperatures $\left(140-200{ }^{\circ} \mathrm{C}\right)$ which leaves behind a solid cake consisting of mainly lignin and decrystallized cellulose $[19,24,25]$. After washing and/or neutralization this cake is incubated with cellulose-degrading enzymes in either citrate or acetate buffer at $\mathrm{pH} 5$ in order to release glucose [26]. As shown in the chromatogram of the supernatant after enzymatic digestion of "pretreated Miscanthus biomass" (Fig. 7a), citrate/citric acid (peak 1) of the citrate buffer is interfering with glucose (peak 2) at lower and higher concentrations on the $50 \mathrm{~mm}$ guard column. Furthermore, sorbitol (peak 3) derived from the commercial enzyme mixture (peak 3) also interferes, but to a much lower extent. Using the $300 \mathrm{~mm}$ column, citric acid (peak 1), glucose (peak 2) and sorbitol (peak 3) can be separated (Fig. 7b). As observed earlier with the glucose/xylose integration (Fig. 6), the attempt to integrate the glucose peak separately (now without the citric acid peak contribution) lead to glucan conversions ("glucan uncorrected") that deviated by $2.7-7.1 \%$ from the ones obtained using the $300 \mathrm{~mm}$ column (Fig. 7d). For example, glucan conversion after $72 \mathrm{~h}$ was $82.4 \%$ (50 mm guard column) vs $77.8 \%$ (300 mm column). At time point $0 \mathrm{~h}$ (Fig. $7 \mathrm{a})$, the observed glucose peak (peak 2) was derived from the enzyme mixture used in the experiment. Therefore, this area had to be subtracted as a blank from the glucose area of following time points. Similar as before (Fig. 6e), if the citric acid and glucose peaks at timepoint $0 \mathrm{~h}$ were integrated as one peak and subtracted from following peaks (citric acid + glucose) the values obtained with the $50 \mathrm{~mm}$ guard column ("glucan corrected") were in the range of 98.7-99.7 \% of the values with the $300 \mathrm{~mm}$ column (Fig. 7d). The glucan conversion after $72 \mathrm{~h}$ was $77.6 \%$ (50 mm guard column) vs $77.8 \%$ (300 mm column). The elution on the $50 \mathrm{~mm}$ guard column is completed after $1.4 \mathrm{~min}$ and is therefore about 9 times faster compared to $12.5 \mathrm{~min}$ with the $300 \mathrm{~mm}$ column.

Using acetate buffer, only sorbitol (peak 3) derived from the commercial enzyme mixture interfered with glucose on the $50 \mathrm{~mm}$ guard column (Fig. 7c) because acetate (acetic acid, peak 4) eluted later at $1.75 \mathrm{~min}$. A "split-peak" integration of glucose (peak 2) and sorbitol (peak 3) is sufficient to obtain glucan conversions within 96.2-99.8 \% of the ones resulting from using the $300 \mathrm{~mm}$ column. The $72 \mathrm{~h}$ conversion was $77.5 \%$ (50 mm guard column) vs $78.5 \%$ (300 mm column) and the run time was again about 9 times faster $(1.8 \mathrm{~min}$ vs $16.5 \mathrm{~min}$ ) (Fig. 7e).

It is noteworthy to mention that the acetate buffered samples can also be run with an analysis time of only 


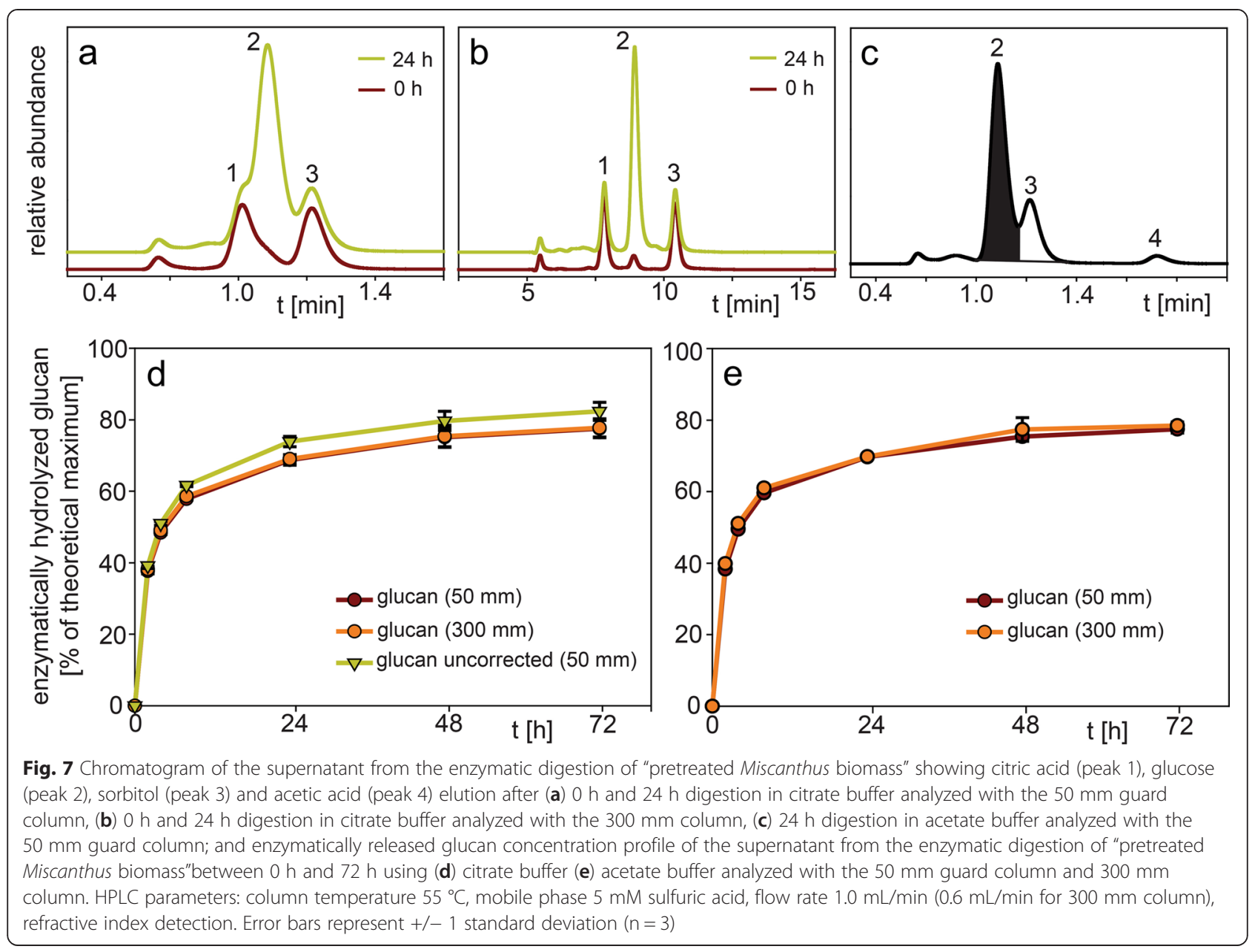

$1.4 \mathrm{~min}$ as the citrate buffered samples. The acetate peak (peak 4) will then be eluted within the first $0.4 \mathrm{~min}$ of the next sample (not interfering with the glucose peak).

Furthermore, the sample analysis time of $1.4 \mathrm{~min}$ is fast enough to compete with other higher-throughput glucose methods like using a YSI bioanalyzer for glucose determination. With the "overlap injection" function of the autosampler, which allows rapid injection of the next sample after a run is completed, about 1000 samples ( $>$ two 384-well plates) can be processed per day.

\section{Application to analysis of ethanol, acetone and $n$-butanol production during acetone-butanol-ethanol (ABE) fermentation}

The analysis of the products from acetone-butanolethanol (ABE) fermentation with a short column is challenging since Clostridia secret a fleet of other compounds (e.g., butyric acid, lactic acid) which can co-elute with the target analytes [8]. The use of an additional UV detector is beneficial for more accurate compound detection and quantification. Fig. 8a shows the chromatogram of a representative sample with RI detection. Ethanol (peak 1) and n-butanol (peak 2) have to be analyzed using the unspecific RI detector. For n-butanol, the concentration profile obtained with the $50 \mathrm{~mm}$ guard column is very similar to the $300 \mathrm{~mm}$ column (Fig. 8d), since interfering compounds were absent or in low concentration at this retention time. The measured n-butanol concentrations were on average $97.0 \%+/-3.8 \%$ (range 98.1-100.3\%) of the values obtained with the $300 \mathrm{~mm}$ column, except for early time points $(<16 \mathrm{~h})$ due to lower concentrations affecting accuracy, and the $90 \mathrm{~h}$ and $112 \mathrm{~h}$ time points with $86.8 \%$ and $105.3 \%$ deviation.

In the $210 \mathrm{~nm}$ UV trace of the same sample (Fig. 8b) a compound (peak 3) is visible that is interfering with the ethanol determination using RI detection (note that in the UV trace a compound had a slightly earlier retention time since the RI detector is in line after the UV detector). However, with the $300 \mathrm{~mm}$ column, peak 3 and ethanol can be separated (data not shown). If ethanol was determined only by RI detection, concentrations were overestimated and the values ranged 117.5-149.3\% (average $126.9 \%+/-8.4 \%$ ) of the values obtained with 


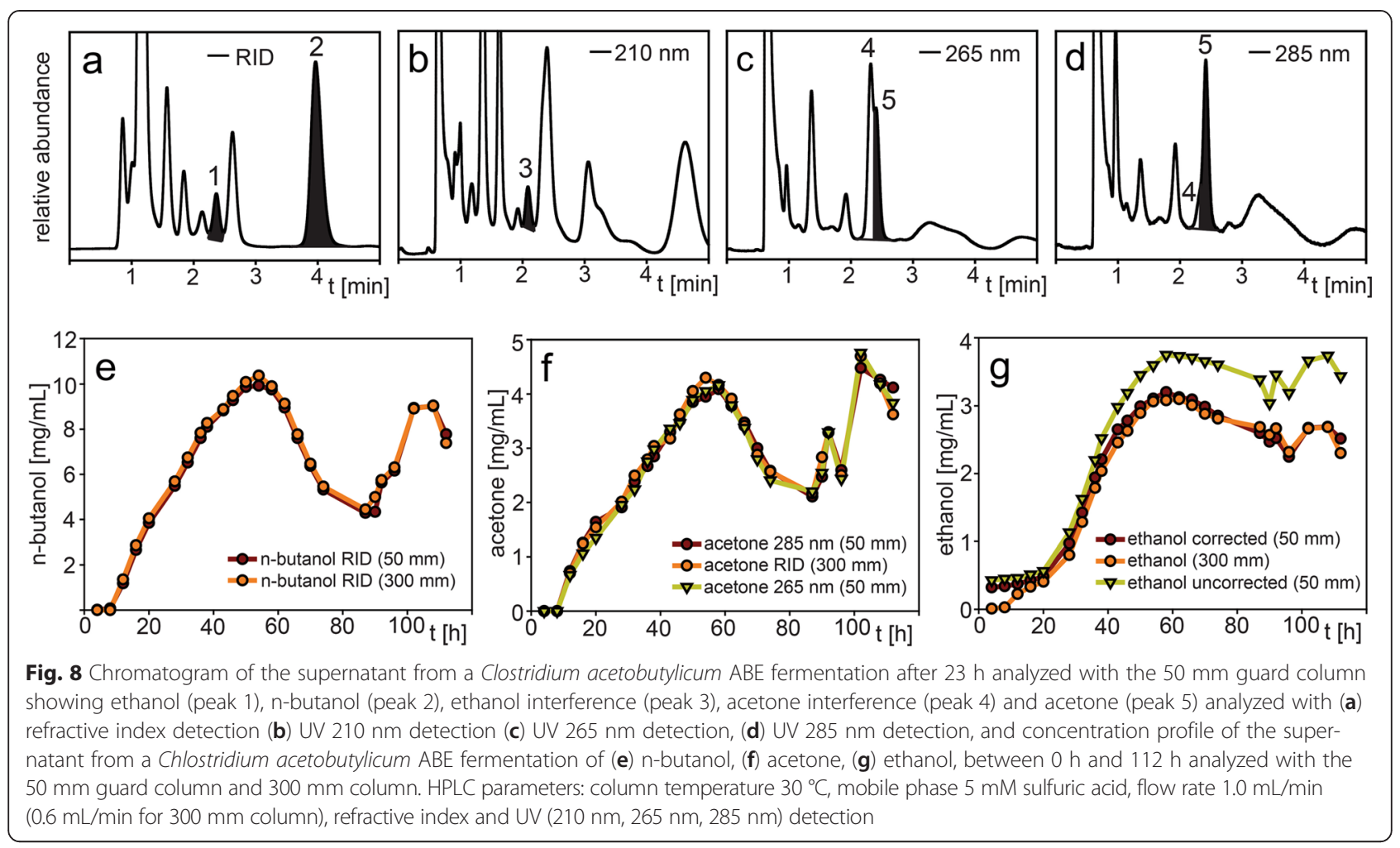

the $300 \mathrm{~mm}$ column (Fig. 8g). The interfering compound was present early in the fermentation process when ethanol production was zero or very minimal. Therefore, it should be possible to measure the area of peak 3 with $210 \mathrm{~nm}$ UV detection and correlate it to the area obtained with RI detection. In this way, the interference of peak 3 in RID mode should be reduced by measuring the sum of the area (ethanol + peak 3) with RID and subtracting the theoretical "RID area contribution" of peak 3 calculated from its $210 \mathrm{~nm}$ UV area. However, we noticed that the low intensity of peak 3 in the earlier time points made correlation of UV and RID signal less accurate. We therefore used an empirical method to determine the UV/RID correlation by adjusting the correlation factor so the corrected ethanol concentration from the $50 \mathrm{~mm}$ guard column best matched the $300 \mathrm{~mm}$ column results. This correction factor was applied to the UV-to-RID conversion of peak 3 at all time-points of the fermentation. "Ethanol corrected" values of average $102.8 \%+/-4.8 \%$ (range 94.6-110.8 \%) of the $300 \mathrm{~mm}$ values were obtained (Fig. 8g), excluding the initial $4-20 \mathrm{~h}$ timepoints.

Acetone (peak 5) is more selectively analyzed at a wavelength of $265 \mathrm{~nm}$ (absorbance maximum) but in the $\mathrm{ABE}$ fermentation sample an interfering peak (peak 4) was present (Fig. 8c). By applying a higher wavelength $(285 \mathrm{~nm})$ the area of the interfering peak was greatly reduced (Fig. 8d). Interestingly, despite the interference, even at $265 \mathrm{~nm}$ good analysis data (average $96.7 \%+/-$ $5.1 \%$, range $85.5-105.8 \%$ of the values using the $300 \mathrm{~mm}$ column, Fig. 8f) was obtained. The results from the $285 \mathrm{~nm}$ detection were similar (average $99.2 \%+/-5.6 \%$, range $87.3-106.5 \%$ of the value using the $300 \mathrm{~mm}$ column, Fig. 8f), excluding the $112 \mathrm{~h}$ time point (113.6\%).

The increase and decrease of the profiles of ethanol, acetone and n-butanol during the course of the fermentation was caused by an applied membrane pervaporation which removed these components from the fermentation medium. During the first $50 \mathrm{~h}$, the microbial production outpaced the membrane removal until the accumulated solvents became toxic to the microorganism and stopped further secretion. At this point, a decline in concentration was observed due to removal by membrane pervaporation (50-90 h). Since the concentration of the solvents was eventually reduced to a sub-toxic level, the cells resumed production of acetone, $n$-butanol and ethanol later in the experiment (90-112 h). Overall, analysis on the $50 \mathrm{~mm}$ guard column was able to monitor these changes with sufficient accuracy and with a sample analysis time of only $5 \mathrm{~min}$ compared to about $45 \mathrm{~min}$ on the $300 \mathrm{~mm}$ column.

\section{Application of the Bio-Rad Micro Guard Cation H guard column}

An even shorter guard column is the $30 \mathrm{~mm} \times 4.6 \mathrm{~mm}$ i.d. Bio-Rad Micro Guard Cation H ("30 mm guard column"). It can be especially well used for the 

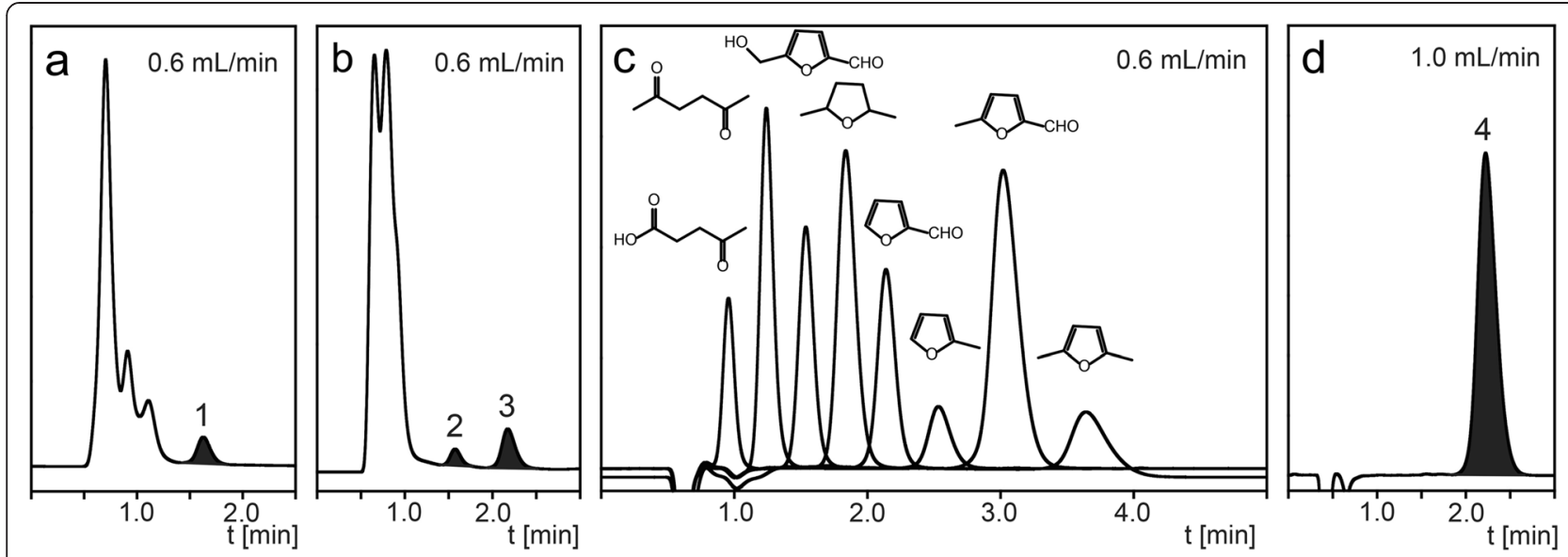

Fig. 9 Chromatogram of (a) the supernatant of Escherichia coli strain DH1 fermentation showing n-butanol (peak 1) elution at $0.6 \mathrm{ml} / \mathrm{min}$ flow rate, (b) the hydrolysate 3 showing 5-HMF (peak 2) and furfural (peak 3) elution at $0.6 \mathrm{ml} / \mathrm{min}$ flow rate, (c) a mixture of levulinic acid, 2,5-hexanedione, 5-HMF, 2,5-dimethyltetrahydrofuran, furfural, methylfuran, 5-methylfurfural and 2,5-dimethylfuran at $0.6 \mathrm{ml} / \mathrm{min}$ flow rate, (d) a standard of n-hexanol (peak 4) at $1.0 \mathrm{ml} / \mathrm{min}$ flow rate, using the $30 \mathrm{~mm}$ guard column. HPLC parameters: column temperature $55^{\circ} \mathrm{C}$, mobile phase $5 \mathrm{mM}$ sulfuric acid, flow rate $0.6 \mathrm{~mL} / \mathrm{min}(1.0 \mathrm{~mL} / \mathrm{min}$ for $\mathrm{n}$-hexanol), refractive index detection

analysis of compounds that elute late on the $300 \mathrm{~mm}$ column. For example, Fig. 9a shows its application to the nbutanol analysis mentioned earlier. The analysis results were very similar to the ones obtained with the $50 \mathrm{~mm}$ guard column with results ranging 92.0-101.8 \% for DH1, 98.2-101.0 \% for DH1 $\triangle a c r B$ and 88.8-91.6 \% for BW25113 profile analysis compared to the $300 \mathrm{~mm}$ column (Fig. $2 \mathrm{~b}$ ). However, by using a standard $0.6 \mathrm{~mL} / \mathrm{min}$ flow rate, the analysis time was cut in half $(2 \mathrm{~min})$ compared to the $50 \mathrm{~mm}$ column (4 min).

Applied to the analysis of 5-HMF and furfural (Fig. 9b), the analysis time (2.5-3 $\mathrm{min})$ was further reduced by more than half compared to the $50 \mathrm{~mm}$ guard column (6-6.5 min, Fig. 4a). Furfural concentrations were slightly higher compared to the $300 \mathrm{~mm}$ column: $100.6 \%$ (1.55 vs $1.54 \mathrm{mg} / \mathrm{mL}), 102.7 \%$ (1.93 vs $1.88 \mathrm{mg} / \mathrm{mL}$ ) and $109.7 \%$ (2.60 vs $2.37 \mathrm{mg} / \mathrm{mL}$ ) for hydrolysate $1-3$, respectively (Fig. 4b). The concentration for 5-HMF was lower for hydrolysate $1(64.7 \%, 0.11 \mathrm{vs} 0.17 \mathrm{mg} / \mathrm{mL})$ and hydrolysate $3(78.4 \%, 0.69$ vs $0.88 \mathrm{mg} / \mathrm{mL})$ but identical for hydrolysate $2(1.40 \mathrm{mg} / \mathrm{mL})$.

An interesting application of this guard column is the analysis of some promising liquid fuel molecules and their precursors [3, 27]. Most of these types of molecules are usually analyzed by gas chromatography. If analyzed by liquid chromatography on the $300 \mathrm{~mm}$ column, the mobile phase has to be modified with a higher concentration of an organic solvent, e.g. acetonitrile, in order to reduce their long retention time [27]. Instead of changing the mobile phase composition, we have explored the reduction of the retention time by using the $30 \mathrm{~mm}$ guard column. Fig. 9c shows the nearly baseline separation of a standard mixture of levulinic acid, 2,5-hexanedione, 5-HMF, 2,5-dimethyltetrahydrofuran, furfural, methylfuran, 5-methylfurfural and 2,5-dimethylfuran, eluting within only $4 \mathrm{~min}$. Since the latter three compounds elute after furfural their elution times are in the range of $1-2 \mathrm{~h}$ on the $300 \mathrm{~mm}$ column (data not shown). Interestingly, despite the structural similarity, especially of the furans, the $30 \mathrm{~mm}$ guard column provided sufficient separation efficiency for these molecules. When the flow rate on the $30 \mathrm{~mm}$ guard column was increased to $1 \mathrm{~mL} / \mathrm{min}$ a further reduction of the analysis time was achieved. At this flow rate, other compounds eluting within the first $25 \mathrm{~min}$ on the $300 \mathrm{~mm}$ column now eluted in less than $1 \mathrm{~min}$ on the $30 \mathrm{~mm}$ guard column (data not shown). For example, the elution of n-hexanol was at $2.3 \mathrm{~min}$ at a flow rate of $1 \mathrm{~mL} / \mathrm{min}$ (Fig. 9d) compared to $96 \mathrm{~min}$ on the standard $300 \mathrm{~mm}$ column (data not shown). In general, the $30 \mathrm{~mm}$ guard column operated at $1.0 \mathrm{ml} /$ min elutes compounds about 4 times faster than the $50 \mathrm{~mm}$ guard column (data not shown). Examples are, e.g., 2,5-dimethylfuran (2.3 vs $10.2 \mathrm{~min}$ ), n-hexanol (2.2 vs $9.3 \mathrm{~min}$ ) and 2,5-dimethyltetrahydrofuran (1.1 vs $4.3 \mathrm{~min}$ ). The $30 \mathrm{~mm}$ guard column can therefore be an ideal tool for the rapid analysis of selected late-eluting compounds. We therefore encourage researchers to explore this guard column for the analysis of compounds that seem to be "invisible" to the RID when injected on the $300 \mathrm{~mm}$ column. This invisibility is most likely due to the effect that compounds remain on the column for a long time and are eluted as broad peaks appearing more like a "baseline-drift", which makes peak detection and compound quantification difficult or impossible.

\section{Conclusion}

We have used examples from various experiments to show that a $50 \mathrm{~mm}$ guard column can be successfully 
used for the analysis of samples from many bioenergyand biotechnology-relevant experimental setups. With this column, samples can be analyzed up to ten-times faster compared to the standard $300 \mathrm{~mm}$ column with very comparable results. Therefore, it is an ideal tool for processing a large amount of samples, such as in screening or discovery experiments. By applying correct peak integration and interference subtraction, concentration profiles from even more complex samples are reliably obtained. A further decrease of the analysis time was achieved by using a $30 \mathrm{~mm}$ guard column that has been shown to be especially suitable for the rapid analysis of compounds with long elution times on the standard $300 \mathrm{~mm}$ column, including biofuel-related alcohols (e.g. n-butanol, n-hexanol) and furan- and tetrahydrofurantype molecules. Owing to the universal applicability and the ease of use as well the numerous citations in the literature, we suspect that almost all labs involved in the fields of biotechnology or biomass conversion technology are equipped with an HPLC-UV/RID instrument and should therefore be able to easily apply the methods presented here. Besides the faster analysis time, guard columns only cost a fraction of their counterparts they were designed to protect. We therefore encourage researchers to explore the feasibility of applying the separation on a guard column to their experimental setup in order to significantly reduce analysis time.

\section{Methods}

\section{HPLC analysis}

Samples were either filtered $(0.45 \mu \mathrm{m})$ or centrifuged (10 min, 14,000 g) and analyzed using a 1200 series high-pressure liquid chromatography system (Agilent Technologies, Santa Clara, CA, USA) consisting of an autosampler with tray cooling, binary pump, degasser, thermostated column compartment, diode array detector (DAD) and refractive index detector (RI) connected in series. The supernatant was injected onto either a $300 \mathrm{~mm} \times 7.8 \mathrm{~mm}$ (length $\times$ inner diameter) Aminex HPX-87H (Bio-Rad, Richmond, CA, USA) column with $9 \mu \mathrm{m}$ particle size, $8 \%$ cross-linkage equipped with a $30 \times$ $4.6 \mathrm{~mm}$ micro-guard Cation $\mathrm{H}$ guard column cartridge (Bio-Rad, Richmond, CA) or onto a $50 \times 7.8 \mathrm{~mm} \mathrm{Rezex}^{\mathrm{mu}}$ RFQ-Fast Acid $\mathrm{H}^{+}$guard column (Phenomenex, Torrance, CA, USA) with $8 \mu \mathrm{m}$ particle size, $8 \%$ cross-linkage or onto a $30 \times 4.6 \mathrm{~mm}$ micro-guard Cation $\mathrm{H}$ guard column cartridge (Bio Rad, Richmond, CA, USA). Compounds were eluted either at 30,55 or $80^{\circ} \mathrm{C}$ at a flow rate of either 0.6 or $1.0 \mathrm{~mL}$ using a mobile phase of $5 \mathrm{mM}$ sulfuric acid.

\section{n-butanol fermentation}

DH1, DH1 $\triangle \mathrm{acrB}$ and BW25113 E. coli strains were inoculated at an OD600 of 0.35-0.45 in $250 \mathrm{~mL}$ screw-capped baffled Erlenmeyer flasks in TB (terrific broth) medium
(1 L contains $12 \mathrm{~g}$ casein peptone, $24 \mathrm{~g}$ yeast extract, $4 \mathrm{~mL}$ glycerol, $2.2 \mathrm{~g}$ potassium phosphate monobasic, $9.4 \mathrm{~g}$ potassium phosphate dibasic, Fisher Scientific, Pittburgh, PA, USA) and grown anaerobically at $30{ }^{\circ} \mathrm{C}$ and $215 \mathrm{rpm}$ for up to $72 \mathrm{~h}$. DH1 $\Delta a c r B$ strain was constructed by removing the efflux pump subunit acrB from the chromosome according to established procedures [28].

\section{iso-butanol fermentation}

sFAB5441 is E. coli Dh5 $\alpha \mathrm{Z} 1$ strain (with LacI and TetR on chromosome) expressing iso-butanol pathway genes. The plasmids for these pathways (pSA55 and pSA69) were obtained from James Liao [29]. Strain sFAB5692 has the same 2 plasmid as sFAB5441 but the genetic background of the strain is AL329 with several deletions (adhE; frdB/frdC; fnr; IdhA; ptA; pflB, adhP, eutG, yiaY, yjgB, betA, fucO, eutE) to improve pyruvate production and iso-butanol yield [30].

All strains were grown aerobically in shake flasks in LB medium and then inoculated in M9 media containing $5 \mathrm{~g} / \mathrm{L}$ yeast extract, $\sim 50 \mathrm{~g} / \mathrm{L}$ glucose, and 1000 -fold dilution of A5 trace metal mix $\left(2.86 \mathrm{~g} \mathrm{H}_{3} \mathrm{BO}_{3}, 1.81 \mathrm{~g} \mathrm{MnCl}_{2} \mathrm{x} 4 \mathrm{H}_{2} \mathrm{O}\right.$, $0.222 \mathrm{~g} \mathrm{ZnSO}_{4} \times 7 \mathrm{H}_{2} \mathrm{O}, 0.39 \mathrm{~g} \mathrm{Na}_{2} \mathrm{MoO}_{4} \times 2 \mathrm{H}_{2} \mathrm{O}, 0.079 \mathrm{~g}$ $\mathrm{CuSO}_{4} \times 5 \mathrm{H}_{2} \mathrm{O}, 49.4 \mathrm{mg} \mathrm{Co}\left(\mathrm{NO}_{3}\right) 2 \times 6 \mathrm{H}_{2} \mathrm{O}$ per liter water $)$ at $37^{\circ} \mathrm{C}$ and grown to an OD600 of 0.6-0.8. Cells were then induced with isopropyl- $\beta$-D-thiogalactopyranoside (IPTG) and then grown at $30^{\circ} \mathrm{C}[29]$.

\section{Pretreated biomass and hydrolysates}

A two-step dilute acid pilot plant pretreatment of Miscanthus X giganteus (around 1 inch size) was performed in a pilot plant at Andritz, Glens Falls, NY. In the first step, the biomass was heat-pretreated with $0.5 \%(\mathrm{w} / \mathrm{w})$ sulfuric acid at $12.5 \%(\mathrm{w} / \mathrm{w})$ solid loading applying a rapid steam-driven heating ramp to $158{ }^{\circ} \mathrm{C}$ and a holding time of $20 \mathrm{~min}$. The liquid was removed from the solids/ pretreated biomass by squeezing out in a hydraulic press and was referred to as "hydrolysate 1 ". In the second step, the pretreated biomass was again heat-pretreated with $1 \%(\mathrm{w} / \mathrm{w})$ sulfuric acid at $12.5 \%(\mathrm{w} / \mathrm{w})$ solid loading applying a rapid steam-driven heating ramp to $180{ }^{\circ} \mathrm{C}$ and a holding time of $4 \mathrm{~min}$. The pressed out liquid from this second stage was referred to as "hydrolysate 2".

Another pretreatment was performed in a pilot plant of the National Renewable Energy Lab (NREL), Golden, CO. Miscanthus X giganteus (around 1 inch size) was heat-pretreated with $1.5 \%(\mathrm{w} / \mathrm{w})$ sulfuric acid at $25 \%$ $(\mathrm{w} / \mathrm{w})$ solid loading applying a rapid steam-driven heating ramp to $190{ }^{\circ} \mathrm{C}$ and a holding time of $1 \mathrm{~min}$ and subsequent rapid pressure release. The pretreated biomass was separated from the mixture by centrifugation and referred to as "pretreated Miscanthus biomass". The obtained liquid phase was referred to as "hydrolysate 3". 


\section{Xylose to ethanol fermentation}

Saccharomyces cerevisiae SA-1-X123 (Brazilian industrial strain) including the X123 cassette for xylose fermentation was grown from an OD600 of 1 in yeast-peptone-xylose (YPX) medium containing $40 \mathrm{~g} / \mathrm{L}$ xylose aerobically at $30{ }^{\circ} \mathrm{C}$ and $100 \mathrm{rpm}$ for $62 \mathrm{~h}[31,32]$.

\section{Glucose to ethanol fermentation}

"Hydrolysate 3" was either adjusted to $\mathrm{pH} 5.5$ with $\mathrm{KOH}$, then centrifuged and filter sterilized or detoxified by $24 \mathrm{~h}$ pervaporation as described previously [21]. Saccharomyces cerevisiae SA-1 was provided by the Yeast Biochemistry and Technology Laboratory, Biological Science Department, Luiz de Queiroz College of Agriculture, University of Sao Paulo, Brazil and was grown at $30{ }^{\circ} \mathrm{C}$ at $200 \mathrm{rpm}$ in $10 \mathrm{~mL}$ of synthetic complete media (SC-80). SC-80 contains $80 \mathrm{~g} / \mathrm{L}$ glucose, $2 \mathrm{~g} / \mathrm{L}$ dropout mix (US Biological, Salem, MA, USA), $6.7 \mathrm{~g} / \mathrm{L}$ yeast nitrogen base (Becton Dickinson, Franklin Lakes, NJ, USA), $19.5 \mathrm{~g} / \mathrm{L}$ 2-ethanesulfonic acid (MES) buffer, and a small amount of $\mathrm{KOH}$ to adjust the $\mathrm{pH}$ to 5.5 . After overnight growth, cells were harvested by centrifugation. Fermentation was performed in $25 \mathrm{~mL}$ Hungate bottles under anaerobic conditions. The fermentation broth contained either $25 \%(\mathrm{v} / \mathrm{v})$ of "hydrolysate 3" or pervaporation-detoxified "hydrolysate 3" (with added water to match the amount removed by pervaporation), with the addition of the components of SC-80 to match SC-80 levels, and harvested SA-1 yeast cells to obtain an initial OD600 of 0.3 . The fermentation was performed at $34{ }^{\circ} \mathrm{C}$ and $200 \mathrm{rpm}$ for $67 \mathrm{~h}$.

\section{Enzymatic digestibility assay}

"Pretreated Miscanthus biomass" was extensively washed with de-ionized water followed by consecutive centrifugation steps until $\mathrm{pH}$ of decanted water reached $\mathrm{pH} 5$. Excess water was then removed from the biomass by manually squeezing the biomass between paper towels. An equivalent of biomass containing $1 \mathrm{~g}$ of cellulose was used in $25 \mathrm{~mL}$ liquid volume digestion reactions (considering water from biomass) in $50 \mathrm{~mL}$ Falcon screw cap tubes. Final digestion reactions contained either $0.05 \mathrm{M}$ sodium citrate buffer ( $\mathrm{pH} 4.8$ ) or $0.05 \mathrm{M}$ sodium acetate buffer ( $\mathrm{pH} 4.8$ ) and 30 FPU cellulase from Trichoderma reesei ATC 26291 (Sigma-Aldrich, St. Louis, MO, USA), 20 U Novozymes 188 (Sigma Aldrich, St. Louis, MO, USA) and $0.02 \%(\mathrm{w} / \mathrm{v})$ sodium azide. The digestion reactions were incubated at $50{ }^{\circ} \mathrm{C}$ and $200 \mathrm{rpm}$ for $72 \mathrm{~h}$.

\section{ABE fermentation and pervaporation}

Fermentations were carried out at $37{ }^{\circ} \mathrm{C}$ and $200 \mathrm{rpm}$ in 3-L bioreactors (Bioengineering AG, Switzerland) with a 2 L working volume [33, 34]. Seed culture of Clostridium acetobutylicum ATCC824 (purchased from the American
Type Culture Collection, Manassas, VA, USA) in clostridia growth medium (CGM, $100 \mathrm{~mL}$ ) was prepared in a $150 \mathrm{~mL}$ anaerobic serum bottle at $37{ }^{\circ} \mathrm{C}$ until OD600 reached 2.0 and $60 \mathrm{~mL}$ of the seed culture was used to inoculate the bioreactor. The bioreactor automatically kept the $\mathrm{pH} \geq 5.0$ during the fermentation, using a $5 \mathrm{M}$ $\mathrm{KOH}$ solution. Nitrogen gas was inserted into the bioreactor at a rate of $200 \mathrm{~mL} / \mathrm{min}$ to maintain an anaerobic environment. Losses of volatiles, through the gas exhaust port, were minimized by using a cooling condenser attached to a RTE7 water bath (Thermo Fisher-Scientific, Sunnyvale, CA, USA) kept at $4{ }^{\circ} \mathrm{C}$. The system was attached to pervaporation laboratory bench test unit built by Sulzer Chemtech, Neunkirchen, Germany.

After $18 \mathrm{~h}$, pervaporation started with a polystyreneblock-polydimethylsiloxane-block-polystyrene (SDS) block copolymer membrane $\left(37 \mathrm{~cm}^{2}, 2 \mu \mathrm{m}\right.$ thickness (on support)) [21]. The fermentation broth of the bioreactor was continuously passed over the membrane and back into the bioreactor by using a peristaltic pump (model \# 7553-70, Cole-Parmer, Vernon, IL, USA,). ABE fermentation by $C$. acetobutylicum occurs in two steps: an acidogenesis phase wherein the microbes mainly produce acetic acid and butyric acid, followed by a solventogenesis phase wherein the microbes mainly produce ABE.

\section{Competing interests}

The authors declare that they have no competing interests.

\section{Authors' contributions}

SB is the academic responsible for funding and supervising the research in addition to coordinating the experimental design, experimental setup, data analysis and drafting the manuscript. ABI performed the experimental setup and data analysis. Both authors read and approved the final manuscript.

\section{Acknowledgements}

This work was funded by the Energy Biosciences Institute. "Hydrolysate 3" and "pretreated Miscanthus biomass" was provided by the National Renewable Energy Laboratory, 1617 Cole Blvd., Golden, CO 80401, a national laboratory of the U.S. Department of Energy managed by the Alliance for Sustainable Energy, LLC for the U.S. Department of Energy under Contract Number DE-AC36-08GO28308. The authors thank Niwen Kong, Vivek Mutalik, Thalita Peixoto Basso, Jeffrey Skerker, Zach Baer, Jon Kuchenreuther, and Eric Sacia for providing samples as well as information on sample generation and on the experimental setup. The authors also thank Mara Bryan for valuable comments and suggestions improving the manuscript. Publication made possible in part by support from the Berkeley Research Impact Initative (BRII) sponsored by the UC Berkeley Library.

Received: 18 December 2014 Accepted: 1 May 2015

Published online: 28 May 2015

\section{References}

1. Erdei B, Barta Z, Sipos B, Réczey K, Galbe M, Zacchi G. Ethanol production from mixtures of wheat straw and wheat meal. Biotechnol Biofuels. 2010;3:16.

2. Saha BC, Iten LB, Cotta MA, Wu YW. Dilute acid pretreatment, enzymatic saccharification and fermentation of wheat straw to ethanol. Process Biochem. 2005;40:3693-700.

3. Román-Leshkov Y, Barrett CJ, Liu ZY, Dumesic JA. Production of dimethylfuran for liquid fuels from biomass-derived carbohydrates. Nature. 2007;447:982-6. 
4. Brandt A, Ray MJ, To TQ, Leak DJ, Murphy RJ, Welton T. Ionic liquid pretreatment of lignocellulosic biomass with ionic liquid-water mixtures. Green Chem. 2012;13:2489-99.

5. Sluiter A, Hames B, Ruiz R, Scarlata C, Sluiter J, Templeton D, Crocker D: Determination of Structural Carbohydrates and Lignin in Biomass. In Laboratory Analytical Procedure (LAP). National Renewable Energy Laboratory (NREL), Golden, CO. Revised Version 2012. http://www.nrel.gov/ biomass/analytical_procedures.html. Accessed November 2014.

6. Scarlata CJ, Hyman DA. Development and validation of a fast high pressure liquid chromatography method for the analysis of lignocellulosic biomass hydrolysis and fermentation products. J Chromatogr A. 2010;1217:2082-7.

7. Buday Z, Linden JC, Karim MN. Improved acetone-butanol fermentation analysis using subambient HPLC column temperature. Enzyme Microb Technol. 1990;12:24-7

8. Kumar M, Saini S, Gayen K. Acetone-butanol-ethanol fermentation analysis using only high performance liquid chromatography. Anal Methods. 2014;6:774-81.

9. Binder JB, Blank JJ, Cefali AV, Raines RT. Synthesis of furfural from xylose and xylan. Chem Sus Chem. 2010;3:1268-72.

10. Cai CM, Nagane N, Kumar R, Wyman CE. Coupling metal halides with a co-solvent to produce furfural and 5-HMF at high yields directly from lignocellulosic biomass as an integrated biofuels strategy. Green Chem. 2014;16:3819-29.

11. Li H, Chai X-S, Deng Y, Zhan H, Fu Z. Rapid determination of ethanol in fermentation liquor by full evaporation headspace gas chromatography. J Chromatogr A. 2009;1216:169-72.

12. Mendes LS, Oliveira FCC, Suarez PAZ, Rubim JC. Determination of ethanol in fuel ethanol and beverages by Fourier transform (FT)-near infrared and FT-Raman spectrometries. Anal Chim Acta. 2003:493:219-31.

13. Vermeir S, Nicolaï BM, Jans K, Maes G, Lammertyn J. High-throughput microplate enzymatic assay for fast sugar and acid quantification in apple and tomato. J Agric Food Chem. 2007;55:3240-8.

14. Birnberg PR, Brenner ML. A one-step assay for sucrose with sucrose phosphorylase. Anal Biochem. 1984;142:556-61.

15. Kristoffersen L, Skuterud B, Larssen BR, Skurtveit S, Smith-Kielland A. Fast quantification of ethanol in whole blood specimens by the enzymatic alcohol dehydrogenase method. Optimization by experimental design. J Anal Toxicol. 2005;29:66-70

16. Velterop JS, Vos F. A rapid an inexpensive microplate assay for the enzymatic determination of glucose, fructose, sucrose, L-malate and citrate in tomato (Lycopersicon esculentum) extracts and in orange juice. Phytochem Anal. 2011;12:299-304

17. Raba J, Mottola HA. Glucose oxidase as an analytical reagent. Critic Rev Anal Chem. 1995;25:1-42.

18. YSI 2950 biochemistry analyzer [http://www.ysilifesciences.com/index.php?page= ysi-2950-biochemistry-analyzer]

19. Wyman CE. Aqueous Pretreatment of Plant Biomass for Biological and Chemical Conversion to Fuels and Chemicals. New York: Wiley; 2013.

20. Ebert J: Furfural: Future feedstock for fuels and chemicals. Biomass Magazine [http://biomassmagazine.com/articles/1950/furfural-future-feedstock-forfuels-and-chemicals]

21. Greer DR, Basso TP, Ibanez AB, Bauer S, Skerker JM, Ozcam AE, et al. Fermentation of hydrolysate detoxified by pervaporation through block copolymer membranes. Green Chem. 2014;16:4206-13.

22. Mitchell VD, Taylor CM, Bauer S. Comprehensive analysis of monomeric phenolics in dilute acid plant hydrolysates. Bioenerg Res. 2014;7:654-69.

23. Ibanez A, Bauer S. Analytical method for the determination of organic acids in dilute acid pretreated biomass hydrolysate by liquid chromatography time-of-flight mass spectrometry. Biotechnol Biofuels. 2014;7:145.

24. Humbird D, Davis R, Tao L, Kinchin C, Hsu D, Aden A, Schoen P, Lukas J, Olthof B, Worley M, Sexton D, Dudgeon D: Process Design and Economics for Biochemical Conversion of Lignocellulosic Biomass to Ethanol: Dilute-Acid Pretreatment and Enzymatic Hydrolysis of Corn Stover. Technical Report NREL/ TP-5100-47764. United States National Renewable Energy Laboratory, US Department of Energy. May 2011.

25. Kumar P, Barrett DM, Delwiche MJ, Stroeve P. Methods for pretreatment of lignocellulosic biomass for efficient hydrolysis and biofuel production. Ind Eng Chem Rev. 2009;48:3713-29.
26. Selig M, Weiss N, Ji Y: Enzymatic Saccharification of Lignocellulosic Biomass. In Laboratory Analytical Procedure (LAP). National Renewable Energy Laboratory (NREL), Golden, CO. 2008. http://www.nrel.gov/biomass/ analytical_procedures.html. Accessed November 2014.

27. Yuan J-P, Chen F. Simultaneous separation and determination of sugars, ascorbic acid and furanic compounds by HPLC-dual detection. Food Chem. 1999;64:423-7

28. Fisher MA, Boyarskiy S, Yamada MR, Kong N, Bauer S, Tullman E. Enhancing tolerance to short-chain alcohols by engineering the Escherichia coli AcrB efflux pump to secrete the non-native substrate n-butanol. ACS Synth Biol. 2014:3:30-40.

29. Atsumi S, Hanai T, Liao JC. Non-fermentative pathways for synthesis of branched-chain higher alcohols as biofuels. Nature. 2008;451:86-90.

30. Rodriguez GM, Atsumi S. Isobutyraldehyde production from Escherichia coli by removing aldehyde reductase activity. Microb Cell Fact. 2012;11:90.

31. Kim SR, Park Y-C, Jin Y-S, Seo J-H. Strain engineering of Saccharomyces cerevisae for enhanced xylose metabolism. Biotechnol Adv. 2013;31:851-61.

32. Kim SR, Skerker JM, Kang W, Lesmana A, Wei N, Arkin AP, et al. Rational and evolutionary engineering approaches uncover a small set of genetic changes efficient for rapid xylose fermentation in Saccharomyces cerevisiae. PLoS One. 2013;8, e57048.

33. Anbarasan P, Baer ZC, Sreekumar S, Gross E, Binder JB, Blanch HW, et al. Integration of chemical catalysis with extractive fermentation to produce fuels. Nature. 2012:491:235-9.

34. Alsaker KV, Paredes C, Papoutsakis ET. Metabolite stress and tolerance in the production of biofuels and chemicals: gene-expression-based systemsanalysis of butanol, butyrate, and acetate stresses in the anaerobe Clostridium acetobutylicum. Biotechnol Bioeng. 2010;105:1131-47.

\section{Submit your next manuscript to BioMed Central and take full advantage of:}

- Convenient online submission

- Thorough peer review

- No space constraints or color figure charges

- Immediate publication on acceptance

- Inclusion in PubMed, CAS, Scopus and Google Scholar

- Research which is freely available for redistribution 